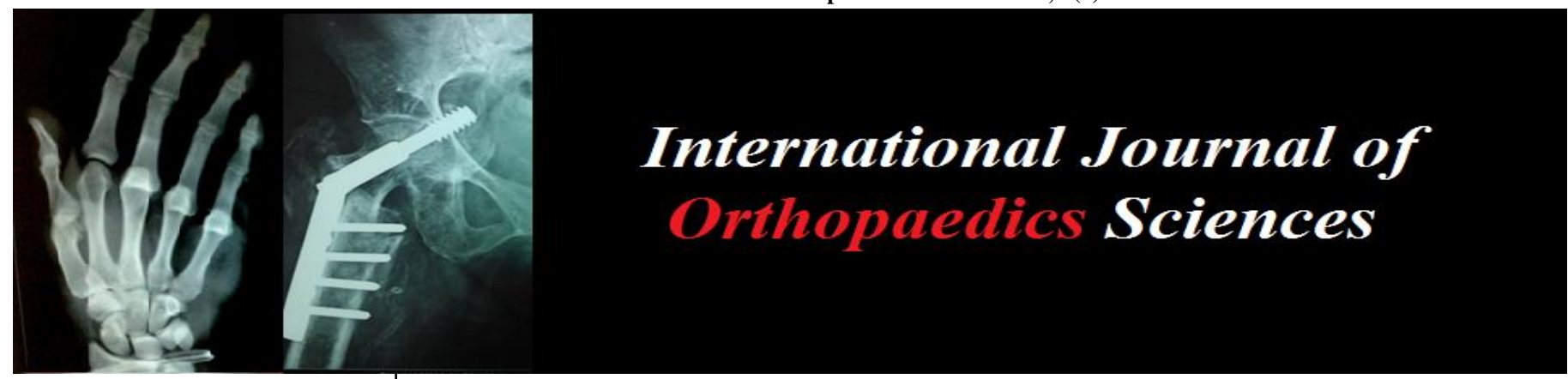

E-ISSN: 2395-1958

P-ISSN: 2706-6630

IJOS 2020; 6(1): 1300-1304

(C) 2020 IJOS

www.orthopaper.com

Received: 10-11-2019

Accepted: 12-12-2019

Dr. Sunil S

MS Ortho, Assistant Professor,

Department of Orthopaedics,

Vydehi Institute of Medical

Sciences \& Research Institute,

Nallurahalli, EPIP, Bengaluru,

Karnataka, India

Dr. Hiranya Kumar S

MS Ortho, Professor \& HOD

Vydehi Institute of Medical

Sciences \& Research Institute,

Nallurahalli, EPIP, Bengaluru,

Karnataka, India

Dr. Muralidhar N

MS Ortho, Professor \& HOD,

Akash Institute of Medical

Sciences \& Research Institute,

Nallurahalli, EPIP, Bengaluru,

Karnataka, India

Dr. Bula Ratna Kuma

Junior Resident, Vydehi

Institute of Medical Sciences \&

Research Institute, Nallurahalli,

EPIP, Bengaluru, Karnataka, India

\section{$A C L$ reconstruction preserving the $A C L$ remnant achieves good clinical outcomes: A case control study}

\author{
Dr. Sunil S, Dr. Hiranya Kumar S, Dr. Muralidhar N and Dr. Bula Ratna \\ Kumar
}

DOI: $\underline{\text { https://doi.org/10.22271/ortho.2020.v6.i1r.2001 }}$

Abstract

Introduction: Orthopaedic surgeons have been trying hard to optimize the technique of ACL reconstruction to have better functional outcome. In addition to stability a high quality of proprioception is also required. The presence of remnant containing mechanoreceptors and free neural endings, can help reinnervate the ACL autograft.

Aims \& Objectives: To compare clinical outcomes in patients undergoing ACL reconstruction with or without remnant preservation.

Materials \& Methods: 86 patients who underwent ACL reconstruction between September 2016 and March 2018. These patients were divided into 2 groups : those in whom the remnant was preserved (group $1=22$ ) and those in whom the remnant was not preserved (group $2=64$ ). Patients were followed up for atleast 18 months.

Results: The Tegner Lysholm score was higher in group 1 than group $2(p<0.05)$. Anterior stability of the knee as measured by Lachman test and Pivot shift test was significantly better in group 1. Post surgery rehabilitation and return to sports was faster in group 1 when compared to group 2 . Graft rupture rates were also significantly lower in group 1.

Conclusion: Remnant preserving ACL reconstruction has higher potential for early healing, superior functional recovery, earlier return to sports and lower incidence of reinjury.

Keywords: ACL, remnant, lachmans test, anterior drawers test, tegner lysholm test

\section{Introduction}

Anterior cruciate ligament (ACL) injury is one of the most common knee injuries. An injured ACL cannot heal naturally and will lead to an increased risk of meniscal injury and osteoarthritis. Thus, ACL reconstruction is a conventional surgical technique to restore function to the knee with a ruptured ACL, and excellent clinical outcomes have been reported. Residual ACL remnants are commonly observed during arthroscopic examination. To identify the ACL attachment, the ACL remnant is debrided clearly during ACL reconstruction using standard techniques. In recent years, the importance of the ACL remnant has been recognized in terms of biomechanical, vascular, and proprioceptive function. Some studies reported that mechanoreceptors that control knee proprioception are located in the inner membrane of the synovium near the tibial attachment of the ACL. In addition, the ACL remnant tissue has good subsynovial and intrafascicular vascularity. This may accelerate cell repopulation and revascularization in the graft.

\section{Materials \& Methods}

86 patients who underwent ACL Reconstruction surgery were included in the study. The period of study was from September 2016 to March 2018. The patients were divided in two groups. Group $1(n=22)$ and Group $2(n=64)$. Mean age of them was 29 years $(13-58)$. Group 1 were patients who had undergone ACL reconstruction without the remnant preservation technique. Group 2 comprised of patients were the ACL remnant from both the femoral and tibial side was preserved [Fig 1].

All patients were operated by a single surgeon (first author). ACL recontruction was done using quadrupled hamstring tendon autograft using the transportal technique.
Corresponding Author: Dr. Sunil S

MS Ortho, Assistant Professor, Department of Orthopaedics, Vydehi Institute of Medical Sciences \& Research Institute, Nallurahalli, EPIP, Bengaluru, Karnataka, India 
The remnants were classified as per the description of Craig et [Fig 2]. The femoral side was fixed using a fixed loop endobutton and the tibial side with interference screw. Accesory anteromedial portal was used to achieve an anatomical femoral tunnel. To establish the femoral bone tunnel we carefully resect the necessary femoral fibres of the torn parts of the AC to visualize the femoral insertion site of the AM or PL. Then we create an adequate low anteromedial portal to establish the femoral bone tunnel. After using the 4.5 $\mathrm{mm}$ Endobutton drill the final diameter of the femoral bone tunnel is usually established by dilatation for not to damage the intact ACL remnants by the head of a drill. Usually the length of the femoral bone tunnel is between $32-40 \mathrm{~mm}$. Consequently we choose a $15 \mathrm{~mm}$ or $20 \mathrm{~mm}$ long Endobutton for femoral fixation. On the tibial side the ACL stump is usually intact. Fixation on the tibial side is performed with a resorbable screw and by fixing the distal fibre-wire sutures over a tibial bone bridge. This is needed because the 3-4 fold graft is to short for screw fixation alone. The result is a double fixation on the tibia.
Postoperatively all patients were put on a long knee brace. Static quadriceps and ankle pump was started on day 0 . Patient was allowed to walk with full weight bearing using crutches from day 1 post operation. sports like running and jogging was started at 2 months.

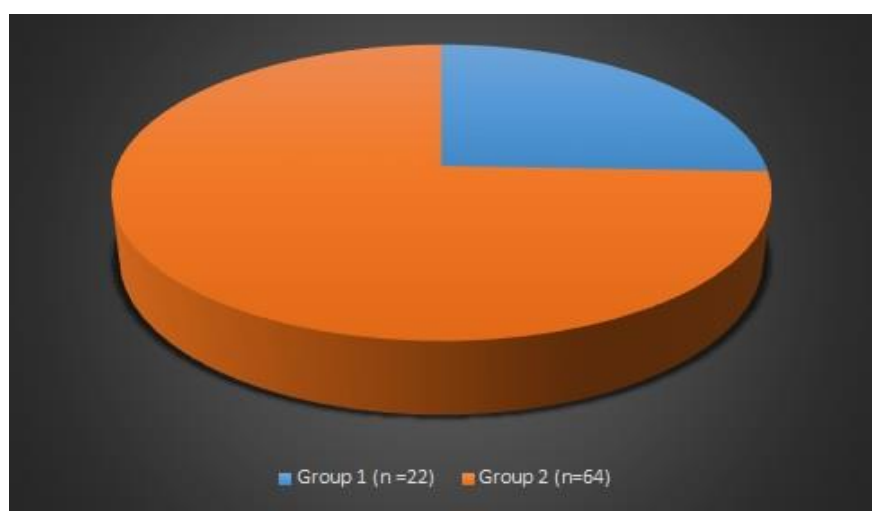

Fig 1: Comparision between the 2 groups

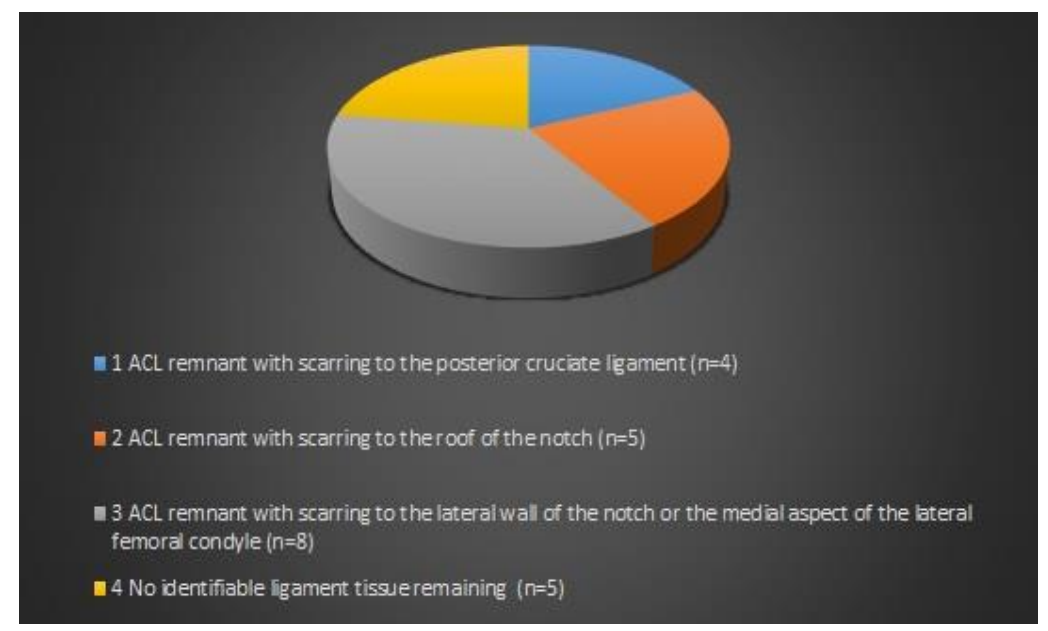

Fig 2: Showing the distribution of the different types of remnants

\section{Results}

Patients were followed up for a period of two years. Preoperative and postoperative assessment was done using the Lachman s test, Anterior Drawer test and Pivot shift test [Fig 3 and Fig 4]. The Lysholm Tegner Knee Score was used to assess the postoperative outcome between the two groups [Fig 5]. Groups were compared using the Mann - Whitney U Test. There was a statistically significant $(p$ value $<0.05)$ in the Lysholm Tegner knee score of the patients belonging to group
1 postoperatively. The patients belonging to group 1 also showed early return to sports and other activities when compared to group 2. There was also reduced graft rupture rates in patients belonging to group 1 .

No Cyclops lesion was noted in any of the cases. Non anatomical femoral tunnels were seen in 3 cases where the accessory anteromedial portal was not used. One superficial infection at the graft site was managed conservatively using local antibiotics.

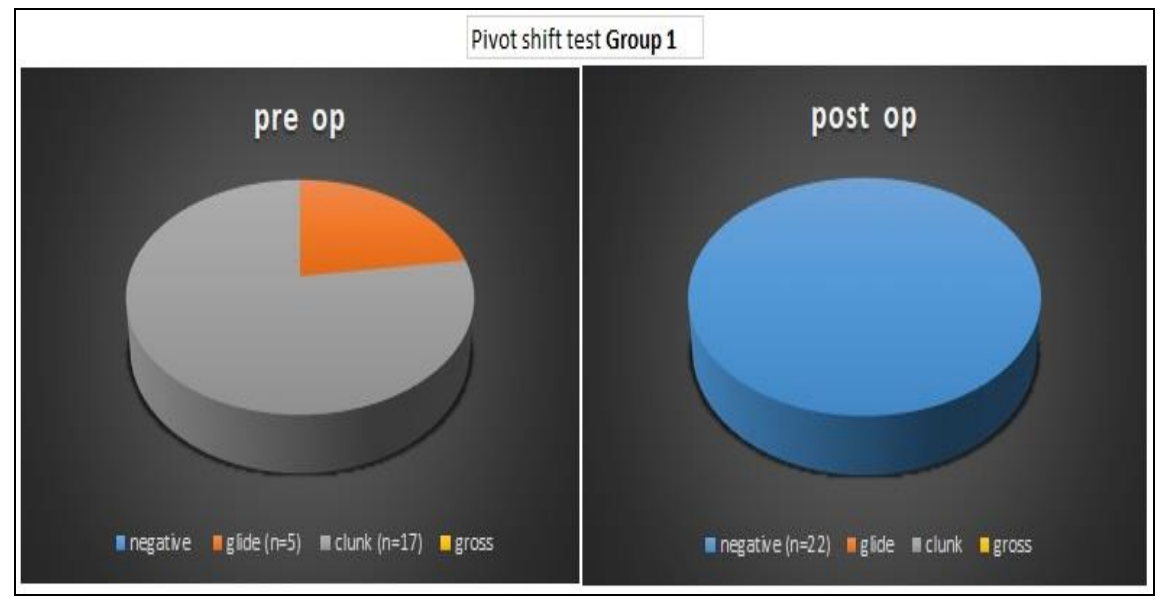

Fig 3: Showing Pivot Shift test of Group 1 


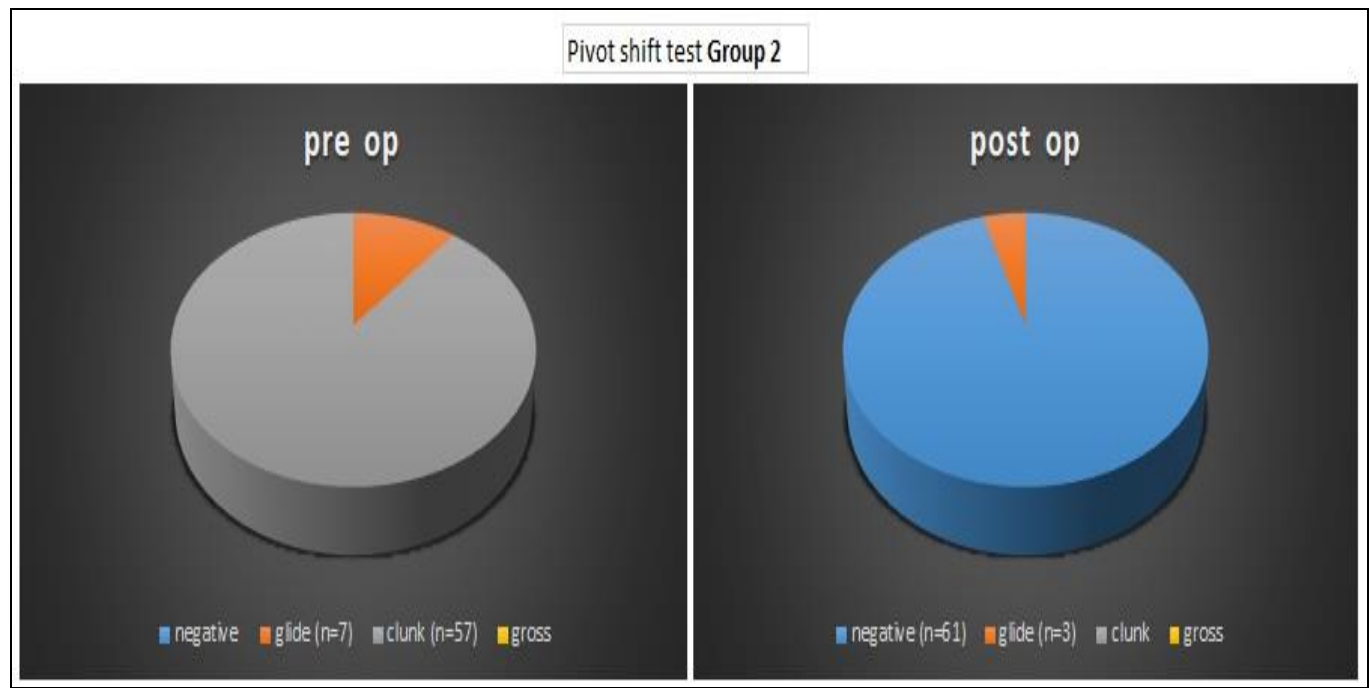

Fig 4: Pivot Shift test of Group 2

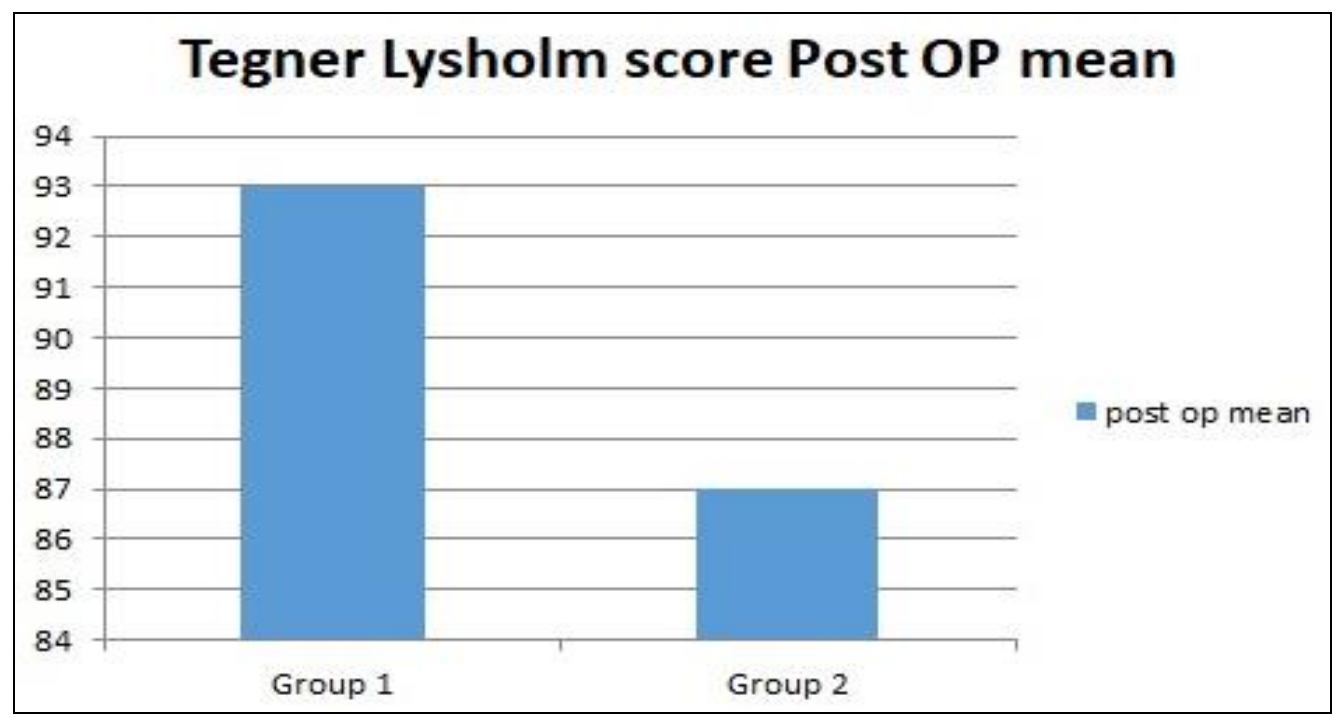

Fig 5: Graph showing the comparision of scores

\section{Discussion}

Remnant preservation has been recognized to have an important role in ACL reconstruction. For patients with ACL injury, the first concern is subjective patient evaluation and complications. The differences in subjective evaluation and complications between the use of the remnant preservation technique and the standard technique (without remnant preservation) play an important role in patient choice.

Some previous studies reported that there are mechanoreceptors located in the subsynovial layer near the tibial site of ACL fibers. Moreover, many authors showed that the regeneration of mechanoreceptors may be accelerated by revascularization of the graft and that the recovery of knee proprioceptive function could be promoted by the surviving mechanoreceptors of the ACL remnant and the regenerated mechanoreceptors. Therefore, some authors have preserved the ACL remnant during ACL reconstruction, assuming that remnant preservation can better restore proprioceptive and functional outcomes of the knee joint. Kondo et al. ${ }^{[9]}$ reported that remnant preservation significantly improved postoperative knee stability and arthroscopic evaluation than using the remnant resecting technique during ACL reconstruction. Lee et al. ${ }^{[10]}$ reported in a group of 16 patients that better proprioceptive and functional outcomes occurred in those with a preserved remnant greater than $20 \%$ of the length of the ACL than in those where the remnant was less than
20\%. Yanagisawa et al. [7] reported that the remnant preservation technique reduces the amount of bone tunnel enlargement. Kitamura et al. demonstrated that the preservation of ACL remnant tissue in anatomic doublebundle ACL reconstruction appears to improve the control of pivot-shift laxity at a minimum of 12 months after surgery.

The remnant ACL tissue has good subsynovial and intrafascicular vascularity. $\mathrm{Wu}$ et al. reported in an experimental study that blood flow to the grafts was significantly higher in the remnant-preserved group than in the remnant-resected group. Therefore, many authors believed that as the remnant was preserved, a portion of blood vessels from the tibial attachment were also preserved, which may accelerate cell repopulation and revascularization in the graft, resulting in acceleration of graft remodeling and early restoration of the mechanical properties of the graft. Ahn et al. reported that magnetic resonance imaging showed significantly larger ACL grafts in the remnant bundle preservation group than in the standard procedure group, and these preserved remnant bundles showed progressive remodeling in the ACL graft. In addition, improved graft remodeling was confirmed by using arthroscopic second-look evaluation. Ahn et al. performed a second-look evaluation in $62 \%$ patients who underwent ACL reconstruction with remnant preservation and reported that $91 \%$ had fair synovialization of the ACL graft. Kondo et al. demonstrated 
on second-look evaluation that the remnant-preserving procedure was significantly better than the remnant-resecting procedure with regard to postoperative laceration or tear of the grafts as well as synovial and fibrous tissue coverage of the grafts. Lu et al. ${ }^{[21]}$ showed that the grafts in the remnant preservation group had a better quality in terms of synovium coverage, apparent tension, and thickness compared with the standard group.

Several studies confirmed that preservation of the remnant during ACL reconstruction can influence the stability of the knee joint, particularly the anterior-posterior stability. Adachi et al. ${ }^{[25]}$ reported that KT-1000 results in remnant-preserved group were $0.7 \pm 1.8 \mathrm{~mm}$ versus $1.8 \pm 2.1 \mathrm{~mm}$ in the standard technique group $(P<0.05)$. Kim et al. reported that the postoperative mean side-to-side difference was $1.67 \mathrm{~mm}$ on KT-2000 in patients who underwent double-bundle ACL reconstruction with the remnant-preserved technique. There are likely several reasons why postoperative knee stability was significantly improved by sufficient preservation of the ACL remnant tissue. The biology of graft healing is a process of creeping substitution. The ACL remnant has good subsynovial and intrafascicular vascularity. Therefore, first, the preserved remnant may accelerate the revascularization and ligamentation of the grafts, as well as its incorporation and stability.

A potential complication of ACL reconstruction using remnant preservation is cyclops syndrome or a cyclops lesion [41-43]. The incidence of cyclops syndrome, which involves serious loss of knee extension caused by a hard nodule around the reconstructed ACL, has been reported to range from 2 to $11 \%$. The incidence of a cyclops lesion, which is a soft synovial tissue mass without any clinical symptoms around the reconstructed ACL, has been reported to range from 2 to $47 \%$. Only one patient required arthroscopic arthrolysis for cyclops syndrome. Some magnetic resonance imaging studies showed that there was no significant difference in the prevalence of cyclops lesion after single-bundle ACL reconstruction between the remnant-preserved and remnantresected techniques $(12.2 \%$ and $15.0 \%$, respectively). Thus, preservation of ACL remnant tissue does not increase the incidence of cyclops lesions.

Our study had a few limitations as it was a small study group with a short follow up period. No tool like the KT 1000 was used to measure the anterior stability. No follow up MRI or Second - look diagnostic arthroscopy was done to assess graft healing.

\section{Conclusion}

Preserving the remnants helps in early healing of the graft, improves functional stability. It reduces the operative time and provides early return to activity.

\section{References}

1. Shelbourne KD, Gray $\mathrm{T}$, Haro $\mathrm{M}$. Incidence of subsequent injury to either knee within 5 years after anterior cruciate ligament reconstruction with patellar tendon autograft. Am J Sports Med. 2009; 37:246-51.

2. Sanders TL, Maradit Kremers H, Bryan AJ, Larson DR, Dahm DL, Levy BA et al. Incidence of anterior cruciate ligament tears and reconstruction: a 21-year populationbased study. Am J Sports Med. 3.

3. Musahl V, Rahnemai-Azar AA, Costello J, Arner JW, Fu $\mathrm{FH}$, Hoshino $\mathrm{Y}$ et al. The influence of meniscal and anterolateral capsular injury on knee laxity in patients with anterior cruciate ligament injuries.
4. Barenius B, Ponzer S, Shalabi A, Bujak R, Norlen L, Eriksson K. Increased risk of osteoarthritis after anterior cruciate ligament reconstruction: a 14-year follow-up

5. Dhillon MS, Bali K, Vasistha RK. Immunohistological evaluation of proprioceptive potential of the residual stump of injured anterior cruciate

6. Bali K, Dhillon MS, Vasistha RK, Kakkar N, Chana R, Prabhakar S. Efficacy of immunohistological methods in detecting functionally viable mechanoreceptors in the remnant stumps of injured anterior cruciate ligaments and its clinical

7. Yanagisawa S, Kimura M, Hagiwara K, Ogoshi A, Nakagawa $\mathrm{T}$, Shiozawa $\mathrm{H}$ et al. The remnant preservation technique reduces the amount of bone tunnel enlargement following anterior cruciate ligament reconstruction.

8. Nakayama H, Kambara S, Iseki T, Kanto R, Kurosaka K, Yoshiya S. Double-bundle anterior cruciate ligament reconstruction with and without remnant preservationcomparison of early postoperative outcomes and complications.

9. Kondo E, Yasuda K, Onodera J, Kawaguchi Y, Kitamura $\mathrm{N}$. Effects of remnant tissue preservation on clinical and arthroscopic results after anatomic double-bundle anterior cruciate ligament reconstruction. Am J Sports Med.

10. Lee BI, Kwon SW, Kim JB, Choi HS, Min KD. Comparison of clinical results according to amount of preserved remnant in arthroscopic anterior cruciate ligament reconstruction using quadrupled hamstring graft. Arthroscopy.

11. McMahon PJ, Dettling JR, Yocum LA, Glousman RE. The cyclops lesion: a cause of diminished knee extension after rupture of the anterior cruciate ligament. Arthroscopy. 1999; 15:757-61.

12. Tonin M, Saciri V, Veselko M, Rotter A. Progressive loss of knee extension after injury. Cyclops syndrome due to a lesion of the anterior cruciate ligament. Am J Sports Med. 2001; 29:545-9.

13. Harris JD, Quatman CE, Manring MM, Siston RA, Flanigan DC. How to write a systematic review. Am J Sports Med. 2014; 42:2761-8.

14. Hozo SP, Djulbegovic B, Hozo I. Estimating the mean and variance from the median, range, and the size of a sample. BMC Med Res Methodol. 2005; 5:13.

15. Higgins J, Green S. Cochrane handbook for systematic reviews of interventions version 5.1.0 [updated March 2011]. Naunyn-Schmiedeberg's Arch Exp Pathol Pharmakol. 2014; 5:S38.

16. Gohil S, Annear PO, Breidahl W. Anterior cruciate ligament reconstruction using autologous double hamstrings: a comparison of standard versus minimal debridement techniques using MRI to assess revascularisation. A randomised prospective study with a one-year follow-up. J Bone Joint Surg Br. 2007; 89:116571.

17. Zhang Q, Zhang S, Cao X, Liu L, Liu Y, Li R. The effect of remnant preservation on tibial tunnel enlargement in ACL reconstruction with hamstring autograft: a prospective randomized controlled trial. Knee Surg Sports Traumatol Arthrosc. 2014; 22:166-73.

18. Demiră B, Ermutlu C, Aydemir F, Durak K. A comparison of clinical outcome of augmentation and standard reconstruction techniques for partial anterior cruciate ligament tears. Eklem Hastalik. Cerrahisi [Joint diseases \& related surgery]. 2012; 23:140-4. 
19. Hong L, Li X, Zhang H, Liu X, Zhang J, Shen JW et al. Anterior cruciate ligament reconstruction with remnant preservation: a prospective, randomized controlled study. Am J Sports Med. 2012; 40:2747-55.

20. Pujol N, Colombet P, Potel JF, Cucurulo T, Graveleau N, Hulet $\mathrm{C}$ et al. Anterior cruciate ligament reconstruction in partial tear: selective anteromedial bundle reconstruction conserving the posterolateral remnant versus singlebundle anatomic ACL reconstruction: preliminary 1-year results of a prospective randomized study. Orthop Traumatol Surg Res. 2012; 98:S171-7.

21. Lu W, Wang D, Zhu W, Li D, Ouyang K, Peng L et al. Placement of double tunnels in ACL reconstruction using bony landmarks versus existing footprint remnant: a prospective clinical study with 2-year follow-up. Am J Sports Med. 2015; 43:1206-14.

22. Andonovski A, Topuzovska S, Samardziski M, Bozinovski Z, Andonovska B, Temelkovski Z. The influence of anterior cruciate ligament remnant on postoperative clinical results in patients with remnant preserving anterior cruciate ligament reconstruction. Open Access Maced J Med Sci. 2017; 5:624-9.

23. Aydog ST, Korkusuz P, Doral MN, Tetik O, Demirel HA. Decrease in the numbers of mechanoreceptors in rabbit ACL: the effects of ageing. Knee Surg Sports Traumatol Arthrosc. 2006; 14:325-9.

24. Lee BI, Min KD, Choi HS, Kwon SW, Chun DI, Yun ES et al. Immunohistochemical study of mechanoreceptors in the tibial remnant of the ruptured anterior cruciate ligament in human knees. Knee Surg Sports Traumatol Arthrosc. 2009; 17:1095-101.

25. Adachi N, Ochi M, Uchio Y, Iwasa J, Ryoke K, Kuriwaka M. Mechanoreceptors in the anterior cruciate ligament contribute to the joint position sense. Acta Orthop Scand. 2002; 73:330-4.

26. Ahn JH, Wang JH, Lee YS, Kim JG, Kang JH, Koh KH. Anterior cruciate ligament reconstruction using remnant preservation and a femoral tensioning technique: clinical and magnetic resonance imaging results. Arthroscopy. 2011; 27:1079-89.

27. Georgoulis AD, Pappa L, Moebius U, Malamou-Mitsi V, Pappa S, Papageorgiou CO et al. The presence of proprioceptive mechanoreceptors in the remnants of the ruptured ACL as a possible source of re-innervation of the ACL autograft. Knee Surg Sports Traumatol Arthrosc. 2001; 9:364-8.

28. Ochi M, Adachi N, Uchio Y, Deie M, Kumahashi N, Ishikawa $\mathrm{M}$ et al. A minimum 2-year follow-up after selective anteromedial or posterolateral bundle anterior cruciate ligament reconstruction. Arthroscopy. 2009; 25:117-22.

29. Kim SJ, Jo SB, Kim TW, Chang JH, Choi HS, Oh KS. A modified arthroscopic anterior cruciate ligament doublebundle reconstruction technique with autogenous quadriceps tendon graft: remnant-preserving technique. Arch Orthop Trauma Surg. 2009; 129:403-7.

30. Lee JH, Bae DK, Song SJ, Cho SM, Yoon KH. Comparison of clinical results and second-look arthroscopy findings after arthroscopic anterior cruciate ligament reconstruction using 3 different types of grafts. Arthroscopy. 2010; 26:41-9.

31. Kitamura N, Yasuda K, Yokota M, Goto K, Wada S, Onodera $\mathrm{J}$ et al. The effect of intraoperative graft coverage with preserved remnant tissue on the results of the pivot-shift test after anatomic double-bundle anterior cruciate ligament reconstruction: quantitative evaluations with an electromagnetic sensor system. Am J Sports Med. 2017; 45:2217-25.

32. Wu B, Zhao Z, Li S, Sun L. Preservation of remnant attachment improves graft healing in a rabbit model of anterior cruciate ligament reconstruction. Arthroscopy. 2013; 29:1362-71.

33. Ahn JH, Lee SH, Choi SH, Lim TK. Magnetic resonance imaging evaluation of anterior cruciate ligament reconstruction using quadrupled hamstring tendon autografts: comparison of remnant bundle preservation and standard technique. Am J Sports Med. 2010; 38:1768-77.

34. Howell SM, Knox KE, Farley TE, Taylor MA. Revascularization of a human anterior cruciate ligament graft during the first two years of implantation. Am J Sports Med. 1995; 23:42-9.

35. Deehan DJ, Cawston TE. The biology of integration of the anterior cruciate ligament. J Bone Joint Surg Br. 2005; 87:889-95.

36. Zaffagnini S, De Pasquale V, Marchesini Reggiani L, Russo A, Agati P, Bacchelli B et al. Neoligamentization process of BTPB used for ACL graft: histological evaluation from 6 months to 10 years. Knee. 2007; 14:8793.

37. Malinin TI, Levitt RL, Bashore C, Temple HT, Mnaymneh W. A study of retrieved allografts used to replace anterior cruciate ligaments. Arthroscopy. 2002; 18:163-70.

38. Wang HD, Gao SJ, Zhang YZ. Comparison of clinical outcomes after anterior cruciate ligament reconstruction using a hybrid graft versus a hamstring autograft. Arthroscopy. 2018; 34(5):1508-16.

39. Adachi N, Ochi M, Uchio Y, Sumen Y. Anterior cruciate ligament augmentation under arthroscopy. A minimum 2year follow-up in 40 patients. Arch Orthop Trauma Surg. 2000; 120:128-33.

40. Tomita F, Yasuda K, Mikami S, Sakai T, Yamazaki S, Tohyama H. Comparisons of intraosseous graft healing between the doubled flexor tendon graft and the bonepatellar tendon-bone graft in anterior cruciate ligament reconstruction. Arthroscopy. 2001; 17:461-76.

41. Sonnery-Cottet B, Lavoie F, Ogassawara R, Kasmaoui H, Scussiato RG, Kidder JF et al. Clinical and operative characteristics of cyclops syndrome after double-bundle anterior cruciate ligament reconstruction. Arthroscopy. 2010; 26:1483-8.

42. Wang J, Ao Y. Analysis of different kinds of cyclops lesions with or without extension loss. Arthroscopy. 2009; 25:626-31.

43. Gohil S, Falconer TM, Breidahl W, Annear PO. Serial MRI and clinical assessment of cyclops lesions. Knee Surg Sports Traumatol Arthrosc. 2014; 22:1090-6. 